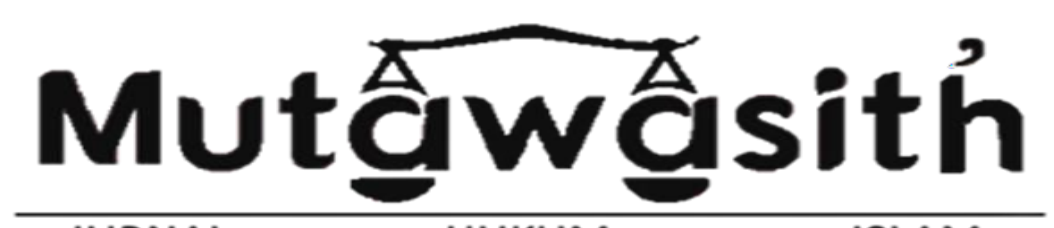

\begin{tabular}{|c|c|c|}
\cline { 2 - 3 } \multicolumn{1}{c|}{ JURNAL } & HUKUM & ISLAM \\
\hline Vol. 3. No. 2 (2020) 07-12 & E-ISSN: : 2723-4681 & P-ISSN: 2722-2764 \\
\hline \multicolumn{2}{|c|}{ Published online on the journal's website: } \\
http://jurnal.iailm.ac.id/index.php/mutawasith
\end{tabular}

\title{
Pemikiran Wahbah al-Zuhaili tentang Hukum Riba dalam Transaksi Keuangan pada Kitab Fiqih Islam Wa Adillatuhu
}

\author{
Nyanyang \\ Institut Agama Islam Latifah Mubarokiyah Tasikmalaya, Indonesia \\ nyanyangpulo@gmail.com
}

\begin{tabular}{|c|c|c|}
\hline Received: & Revised: & Published: \\
\hline 06-11-2020 & $11-11-2020$ & $15-12-2020$ \\
\hline \multicolumn{2}{|c|}{ DOI: https://doi.org/ 10.47971/mjhi.v3i2.234 } \\
\hline
\end{tabular}

\begin{abstract}
This research journal describes the problem of usury from a legal perspective and its interpretation that occurs in financial transactions in financial institutions and personal financial transactions carried out by the public, one of which is from financial transactions in insurance institutions and bank interest from Wahbah Zuhaili's thought and provides a solution. According to him, usury is divided into three types. First, fadh riba, second, yad usury and third usury nasiah. Wahbah Zuhaili argues that the forbidden interest is usury which multiplies either the amount or the amount of interest earned because it is the same as the element of rib. The prohibition of usury (usurios) in Islam is based on moral and human considerations because the essence of prohibiting usury is the elimination of all forms of economic practices that cause injustice and injustice. And the impact of interest on the economy will hamper economic growth. The method of writing this journal is based on literature review by conducting an in-depth review of the works of Wahbah Zuhaili, books, interpretations and writings on bank interest, usury and related to it. The purpose of this paper is to find out the laws, practices of usury and solutions in order to avoid the practice of usury caused by the interest system on the economy.
\end{abstract}

Keywords: Riba, al-Fiqih, Transactions, Financial

\section{Abstrak}

Artikel ini menjelaskan tentang permasalahan riba dari segi hukum dan penafsirannya yang terjadi dalam Transaksi Keuangan dalam lembaga keuangan dan transaksi keuangan secara personal yang dilakukan oleh masyarakat, salah satunya dari transaksi keuangan dalam lembaga asuransi serta bunga bankdari pemikiran wahbah zuhaili serta memberikan solusinya. Menurutya, riba terbagi menjadi beberapa bagian: riba fadh, riba qard, riba yad, dan riba nasiah. Wahbah zuhaili berpendapat bahwa bunga diharamkan adalah riba yang berlipat baik sedikit maupun besar bunga yang didapatkan karena hal, sama dengan unsur rib. Pengharaman riba (usurios) dalam Islam berdasarkanpertimbangan-pertimbangan moral dan kemanusiaan sebab esensi pelarangan riba adalahpenghapusan segala bentuk praktik ekonomi yang menimbulkan kezaliman danketidakadilan. Dan dampak bunga terhadap perekomian akan menyebabkanterhambatnya pertumbuhan ekonomi. Metode penulisan jurnal ini berdasarkan kajian pustaka dengan melakukan review secara mendalam terhadap kitab karya wahbah zuhaili, buku-buku, tafsir dan tulisan-tulisan tentang bunga bank, riba 
dan yang berkaitan dengannya. Tujuan penulisan ini adalah untuk mengetahui hukum, praktik riba dan solusi agar terhindar dari praktik ribaditimbulkan sistem bunga terhadap perekonomian.

Kata Kunci: Riba, Fiqh, Transaksi, Keuangan

\section{PENDAHULUAN}

Agama Islam diturunkan untuk menjawab persoalan manusia. Ajaran agama Islam harus dilaksanakan dalam segala aspek kehidupan. Agama Islam tidak hanya bertindak pada tataran normatif yang membahas mengenai moralitas semata. Agama Islam adalah agama amal, sehingga penafsirannya pun harus beranjak dari normatif menuju teoritis keilmuan yang faktual. Selain Itu agama Islam ada perintah untuk melakukan sistem pencatatan yang tujuan utamanya adalah kebenaran, kepastian, keterbukaan, dan keadilan antara kedua pihak yang memiliki hubungan muamalah. Salah satunya adalah hukum riba yang terdapat dalam transaksi keuangan.

Bisnis Islami dikendalikan oleh aturan syariah, seperti berupa halal dan haram, baik dari cara memperolehnya maupun pemanfaatannya. Sementara Bisnis non-Islami dilandaskan pada sekularisme yang bersendikan pada nilai-nilai material. Bisnis non-Islami tidak memperhatikan aturan halal dan haram dalam setiap perencanaan, pelaksanaan dan segala usaha yang dilakukan dalam meraih tujuan bisnis. Disini dapat dilihat bahwa bisnis secara Islami lebih baik apabila dibandingkan dengan bisnis non slami yang cara mencapai tujuan bisnisnya tidak mementingkan apakah itu halal atau haram, merugikan orang lain atau tidak sudah tidak diindahkan lagi, yang terpenting tujuan bisnis mereka tercapai. Sedangkan bisnis Islam memiliki aturan-aturan yang mengatur agar tidak ada salah satu pihak yang dirugikan seperti dicontohkan oleh Rasulullah SAW yang apabila melakukan transaksi bisnis beliau selalu jujur dan adil baik itu kepada pembeli (konsumen) maupun kepada mitra bisnisnya. ${ }^{1}$ Selain itu, makan dan minum merupakan kebutuhan primer bagi manusia, artinya tidak dapat dipisahkan dalam kehidupan manusia, karena manusia butuh makan dan minum untuk bertahan hidup. Dalam memenuhi kebutuhan konsumen, para pengusaha mengeluarkan produk yang berkualitas serta harga terjangkau untuk ditawarkan kepada para konsumen tanpa mengandung unsur riba. ${ }^{2}$

Riba dalam konsep bisnis Islam dikenal sebagai tambahan yang tidak disertai dengan adanya pertukaran kompensasi2dilarang oleh al-Qur"an. Al-Qur"an sendiri telah menjelaskan secara rinci tahapan pelarangan riba tersebut. Tahap pertama sekedar menggambarkan adanya unsur negatif dalam riba (QS. al-Rum[30]:39). Kemudian disusul dengan isyarat keharaman riba dengan disampaikannya kecaman terhadap orang-orang Yahudi yang melakukan praktikriba (QS. al-Nisa"[4]:161). Berikutnya, secara eksplisit alQur"an mengharamkan riba dengan batasan adh,,āfanmudhā,,afan(QS. Ali Imran[3]: 130)

\footnotetext{
1 Jamaludin, J., \& Gozali, D. (2018). Etika Bisnis Islam di Kalangan Pedagang Pasar Manaqib TQN Suryalaya. Mutawasith: Jurnal Hukum Islam, 1(1), hlm. 3-4

2 Hadaliah, L. D., \& Maryani, S. (2020). Pengaruh Label Halal Terhadap Pilihan Konsumen Gerai Indomart Panumbangan Kabupaten Ciamis. Mutawasith: Jurnal Hukum Islam, 3(1), hlm. 88
} 
yang diikuti dengan pengharaman riba secara total dalam berbagai bentuknya (QS. alBaqarah[2]:275-281). ${ }^{3}$

Dalam melakukan transaksi keuangan tentunya tidak terlepas dari adanya hubungan perjanjian (akad) yang dilakukan antara pihak pembeli dengan pihak perjual. Oleh karenanya, pada tahapan aplikasinya suatu kelebihan yang muncul akibat adanya kegiatan transaksi sering dikenal dengan istilah riba, kelebihan, bunga, interest, dan istilah lainnya yang semakna dengan konsep riba. Secara bahasa riba dimaknai dengan tambahan, karena salah satu perbuatan riba adalah meminta tambahan dari sesuatu yang dihutangkan. Dari istilah lingustik, riba adalah tumbuh dan membesar. Riba dalam bahasa Inggis (usury) yang berarti suku bungayang lebih dari biasanya atau suku bunga yang mencekik. Secara terminologi fiqih riba adalah tambahan khusus yang dimiliki salah satu dari dua pihak yang terlibat transaksi tanpa ada imbalan tertentu.

Terdapat sistem nilai Islam masyarakat itu yang melandasi setiap aktivitas masyarakat, baik pribadi maupun komunal. Hal ini tidak ditemukan dalam kehidupan masyarakat barat. Perbedaan dalam budaya dan sistem nilai ini menghasilkan bentuk masyarakat, praktik, serta pola hubungan yang berbeda pula. Salah satu perbedaan budaya sistem ajaran Islam dengan ajaran agama lain adalah soal tujuan dan konsep transaksi keuangan yang menjadi kegiatan manusia sehari-hari. Tujuan dalam transaksi keuangan syariah adalah terciptanya peradaban bisnis dengan wawasan humanis, emansipatoris, transendental, dan teologis. Dengan transaksi keuangan, realitas sosial yang dibangun mengandung nilai tauhid dan ketundukan kepada ketentuan Allah SWT. ${ }^{4}$

Transaksi keuangan, layaknya dalam suatu perekonomian, apapun sistem ekonomi yang dipakai hubungan antar pihak yang melakukan kegiatan ekonomi akan berakhir dengan transaksi (transaction). Secara umum, transaksi dapat diartikan sebagai kejadian ekonomi/ keuangan yang melibatkan paling tidak dua pihak (seseorang dengan seseorang atau beberapa orang lainnya) yang saling melakukan pertukaran, melibatkan diri dalam perserikatan usaha, pinjam-meminjam dan lain-lain atas dasar suka sama suka atau pun atas dasar suatu ketetapan hukum/syariat yang berlaku. $^{5}$

Ekonomi Syariah atau yang juga dikenal dengan ekonomi Islam merupakan nilai-nilai sistem ekonomi yang dibangun berdasarkan ajaran Islam, sebagaimana Muhammad bin Abdullah al-Arabi mendefinisikan" "Ekonomi Islam adalah kumpulan prinsip-prinsip umum tentang ekonomi yang diambil dari al-Quran dan Sunnah, dan fondasi ekonomi yang dibangun diatas dasar pokok-pokok tersebut dengan mempertimbangkan kondisi lingkungan dan waktu". ${ }^{7}$

Menurut as-Shiddiqi, ${ }^{8}$ dalam hukum Islam terdapat lima asas yang dijadikan fondasi dalam pembentukan hukum Islam, yaitu:

\footnotetext{
${ }^{3}$ Ghofur, Abdul. "Konsep Riba dalam Al-Qur'an." Economica: Jurnal Ekonomi Islam 7.1 (2016), hlm. 1

${ }^{4}$ Amir Abyan, Fiqih Muamalah,(Semarang: Toha Putra, 2006,) hlm. 39

${ }^{5}$ Moh Rifai, Mutiara Fiqih, (Semarang : CV. Wicaksana, 1998) hlm.777-778

${ }^{6}$ Abdullah Abd al-Husain al-tariqi, Ekonomi Islam: Prinsip, Dasar dan Tujuan, Terjemahan, (Yogyakarta: Magistra Insania Press, 2004), hlm. 14

${ }^{7}$ Abdul Rahman Ghazaly, dkk. Fiqih Muamalat, (Jakarta: Kencana Prenada Media Grup, 2010), hlm. 220.

${ }^{8}$ Hasbi as-Shiddiqi, Filsafat Hukum Islam (Bandung : Bulan Bintang, 1975). hlm. 98
} 
1. Persamaan (al-musawa),

2. Keadilan (al-'adalah),

3. Kemaslahatan (al-maslahah),

4. Tidak memberatkan, dan

5. Pertanggungjawaban personal langsung.

Menurut sistem ekonomi Islam, transaksi senantiasa harus dilandasi oleh aturan hukum-hukum Islam (syariah), karena transaksi adalah manifestasi amal manusia yang bernilai ibadah dihadapan Allah SWT. Sistem dalam transaksi keuangan syariah merupakan bagian dari upaya memelihara harta agar harta yang dimiliki seseorang diperoleh dan digunakan sesuai dengan ketentuan Syariah. ${ }^{9}$ Dalam QS. An-Nisa:29, Allah SWT berfirman:

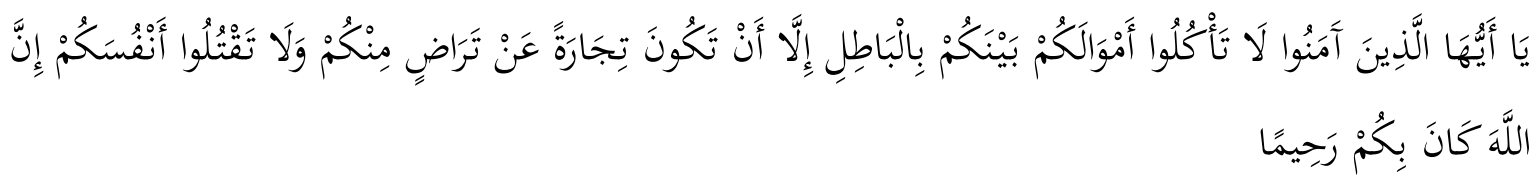

"Hai orang-orang yang beriman, janganlah kamu saling memakan harta sesamamu dengan jalan yang bathil, kecuali dengan jalan perniagaan yang berlaku dengan suka sama suka diantara kamu dan janganlah membunuh dirimu. Sesungguhnya Allah adalah maha penyayang kepadamu". ${ }^{10}$

Harta yang dimiliki oleh setiap orang merupakan titipan dari Allah SWT yang akan dimintai setiap pertanggungjawabannya. Adanya aturan ketentuan syariah bertujuan agar tercapai kemaslahatan bagi setiap orang. Dalam pandangan Islam, hak milik dalam arti harta merupakan hak secara penuh yang di dalamnya ada keperluan untuk dijaga dan digunakan kepada hal-hal yang baik. Firman Allah SWT QS. al-Maidah:120:

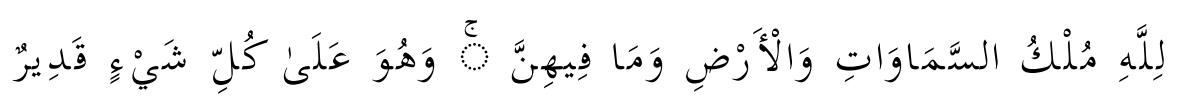

"Kepunyaan Allah-lah kerajaan langit dan bumi dan apa yang ada di dalamnya dan Dia Maha Kuasa atas segala sesuatu."11

Sehingga dalam Islam, transaksi dapat dikategorikan menjadi dua, yakni :

a. Transaksi yang halal dan

b. Transaksi yang haram

\section{METODE}

Dalam penelitian ini yang dilakukan pendekatan secara analisis kualitatif yang meneliti kepustakan (library research), penelitian yang dilaksanakan menggunakan literatur (kepustakaan) yang meneliti pemikiran Wahbah Zuhaili tentang riba transaksi keuangan

\footnotetext{
${ }^{9}$ Abdul Aziz Muhammad Azim, Fiqh Muamalat, (Jakarta: Amzah, 2010). hlm. 216

${ }^{10}$ Departemen Agama RI, Al Qur'an dan Tafsirnya ( Jakarta: Lembaga Percetakan Departemen Agama RI, 2009).

${ }^{11}$ Departemen Agama RI, Al Qur'an dan Tafsirnya ( Jakarta: Lembaga Percetakan Departemen Agama RI, 2009).
} 
atau sejenisnyabaik berupa buku, catatan, maupun laporan hasil penelitian dari penelitian terdahulu.

\section{Jenis Data}

Sebagai bahan dalam penelitian ini yang diajukan terhadap permasalahan transaksi keuangan dalam lembaga keuangan dan dalam sosialitas mayarakat, maka jenis data subyek penelitian adalah orang, tempat, atau benda yang diamati dalam rangka penyusunan sebagai sasaran. Adapun subyek penelitian dalam penelitian ini adalah Wahbah Zuhaili dan salah satu karyanya yaitu kitab al-Fiqh al-Islām wa Adillatuhu.

\section{Teknik Pengumpulan Data}

Pengumpulan data dalam penelitian ini mengunakan cara menganalisis karya Wahbah Zuhaili dalam bidang ilmu fiqih yang terdapat dalam salah satu karyanya yaitu Kitab al-Fiqh al-Islam Wa Adillatuhu.

\section{Analisa Data}

Sesudah bahan untuk penelitian ini dikumpulkan, kemudian dianalisa secara seksama dengan menggunakan analisa kulitatif dengan logika indukatif dan diolah secara menyeluruh bertujuan menganalisa data dan kutipan-kutipan yang bersifat khusus dalam permasalahan peneitian ini. Kemudian dari hasil analisa data yang didapatkan lalau dideskripsikan secara tersusun dan diteliti sesuai dengan permasalahan yang diteliti.

\section{HASIL DAN PEMBAHASAN}

\section{Kilas Biografi Wahbah al-Zuhaili}

Wahbah al-Zuhaili dilahirkan pada tahun 1932 M, bertempat di Dair 'Atiyah kecamatan Faiha, propinsi Damaskus Suriah. Nama lengkapnya adalah Wahbah bin Musthafa al-Zuhaili, anak dari Musthafa al-Zuhaili. Beliau seorang petani sederhana yang terkenal dalam keshalihannya. ${ }^{12}$ Sedangkan ibunya bernama Hajjah Fatimah binti Mustafa Sa'adah. Seorang wanita yang memiliki sifat warak dan teguh dalam menjalankan syari'at agama. Wahbah alZuhaili adalah seorang tokoh di dunia pengetahuan, selain terkenal di bidang tafsir beliau juga seorang ahli figh. Hampir dari seluruh waktunya semata-mata hanya difokuskan untuk mengembangkan bidang keilmuan. Beliau adalah ulama yang hidup diabad ke-20 yang sejajar dengan tokoh-tokoh lainya, seperti Thahir ibnu Asyur, Said Hawwa, Sayyid Qutb, Muhammad abu Zahrah, Mahmud Syaltut, Ali Muhammad al-Khafif, Abdul Ghani, Abdul Khaliq dan Muhammad Salam Madkur. ${ }^{13}$

Perhatian beliau diberbagai ilmu pengetahuan tidak hanya menjadikan beliau aktif dalam menimba ilmu, akan tetapi mejadikan beliau juga sebagai tempat merujuk bagi generasi-generasi setelahnya, dengan berbagai metode dan kesempaatan yang beliau lakukan, yakni melalui berbagai pertemuan majlis ilmu seperti perkuliahan, majlis ta'lim, diskusi, ceramah, dan melalui media massa. Hal ini menjadikan beliau banyak memiliki murid-muridnya, di antaranya adalah Muhammad Faruq Hamdan, Muhammad Na'im Yasin,

\footnotetext{
12 Saiful Amin Ghofur, Profil Para Mufasir al-Qur'an, (Yogyakarta: Pustaka Insan Madani, 2008), hlm. 174

${ }^{13}$ Lisa Rahayu, Makna Qaulan dalam al-Qur'an; Tinjauan Tafsir Tematik Menurut Wahbah al-Zuhailī, (Skripsi Sarjana, Fakutas Ushuluddin Univesitas UIN SUSKSA Riau: Pekanbaru, 2010), hlm. 18
} 
'Abdul al-Satar Abu Ghadah, 'Abdul Latif Farfur, Muhammad Abu Lail, dan termasukalah putra beliau sendiri yakni Muhammad Zuhaili, serta masih banyak lagi murid-muridnya ketika beliau sebagai dosen di Fakultas Syari'ah dan perguruan tinggi lainnya. Meskipun karyanya banyak dalam bidang tafsir dan fiqh akan tetapi dalam penyampaiannya memiliki relefansi terhadap paradigma masyarakat dan perkembangan sains. Di sisi lain, beliau juga aktif dalam menulis artikel dan buku-buku yang jumlahnya hingga melebihi 133 buah buku. Bahkan, jika tulisan-tulisan beliau yang berbentuk risalah dibukukan maka jumlahnya akan melebihi dari 500 makalah. ${ }^{14}$

Dalam setiap buku karangan yang ditulis Wahbah Al-Zuhaili selalu di dasarkan atas dalil yang benar dari Al-Quran, Sunnah, Ijma dan Qiyas. Namun dalam melengkapi proses ijtihad yang dilakukan oleh Wahbah al-Zuhaili, sebaigai seorang ulama kontemporer, beliau terlebih dahulu melakukan kajian terhadap nash-nash yang terdapat dalam al-Quran dengan menggunakan pendekatan disiplin ilmu yang berhubungan seperti ilmu bahasa dengan memperhatikan kata-kata mujmal, musytarak, atau lafazh yang diragukan termasuk lafazh yang amm atau khashsh, haqiqah atau majaz, haqiqah atau urf, muthlaq atau muqayyad, jika ia menemukan nash yang jelas mengenai masalah yang dikajinya, maka ia berpegang teguh pada nash tersebut dan menghukumi masalah yang sedang dikajinya dengan ketentuan yang ada dalam nash-nash itu.

Sedangkan apabila ia tidak menemukannya dalam Al-Quran, maka ia mencari dalam sunnah Rasul yang berupa perkataan (qauliyah). Apabila ia tidak menemukannya dalam hadits qauliyah, ia mencarinya dalam hadits yang berupa perbuatan (amaliyah) yang mencakup perilaku Nabi SAW, seperti tata cara shalat, puasa, haji, dan sebagainya. Jika ia tidak menemukannya dalam keduanya maka ia mengambil hadits yang berupa penetapan (taqririyah) atau penilaian Nabi SAW terhadap apa yang diucapkan atau dilakukan para sahabat yang perkataan atau perbuatan mereka tersebut diakui dan dibenarkan oleh Nabi SAW. Contohnya hadits berikut, seorang sahabat berkata;

Kami (Para sahabat) melakukan shalat dua rakaat sesudah terbenam matahari (sebelum shalat maghrib), Rasulullah SAW terdiam ketika melihat apa yang kami lakukan, beliau tidak menyuruh juga tidak melarang kami (HR. Muslim). Apabila ia menemukan dalam hadits tersebut tentang hukum dari masalah yang sedang dikajinya maka ia menggunakan hadits amaliyah atau taqririyah itu sebagai dalil atau sumber hukum.

Jika dari kedua sumber tersebut ia tidak menemukan kepastian hukum dari masalah yang sedang dikaji, al-Zuhaili kemudian memperhatikan beberapa pendapat-pandapat ulama dengan memperhatikan hadits yang dijadikan dalil oleh para ulama tersebut antara shahih dan dhoifnya dengan cara ia melakukan pen-takhrij-an dan pentahqiq-kan agar hadits-hadits tersebut dapat diketahui shahih dan dhoifnya sehingga bisa memilih pendapat yang bersandar pada hadits shahih. ${ }^{15}$ Kemudian al-Zuhaili melakukan tarjih ${ }^{16}$ terhadap pendapat yang mengacu pada sandaran dalil yang shahih, atau jika hadits yang digunakan

\footnotetext{
${ }^{14}$ http://eprints.stainkudus.ac.id/1154/7/7.\%20BAB\%204.pdf. Diakses pada tanggal 12 Agustus 2020.

${ }_{15}$ Wahbah Zuhayli, al-Figh al-Islam wa Adillatuh, juz 1 (Damaskus: Dar al-Fikr 2006), hlm. 10

${ }^{16}$ Rahmat Syafe'i, Ilmu Ushul Fiqih, cet.5, (Bandung: Pustaka Setia, 2015), hlm. 243-244
} 
sebagai dalil oleh para ulama tersebut mempunyai kekuatan yang sama dalam derajat hadits, maka beliau lebih memilih pendapat yang mempunyai potensi lebih untuk menimbulkan kemaslahatan dan menolak kerusakan.

Jika al-Zuhaili tidak melakukan tarjih terhadap beberapa pendapat ulama, ia lebih mengutamakan untuk mengamalkan pendapat jumhur ulama, alasannya dukungan para ulama terhadap satu pendapat dapat dijadikan alasan kuat dalam pen-tarjih-an. Jika tidak menemukannya dalam beberapa pendapat ulama, ia melakukan qiyas dengan ilhaq atau mempertemukan masalah yang sedang dikajinya dengan masalah yang sudah mempunyai ketentuan hukum dari sumbernya yang mempunyai kesamaan illat. Kemudian ia menghukumi masalah yang dikajinya, dengan hukum yang sama dengan masalah yang sudah mempunyai ketentuan hukum dari sumbernya. Selain dari itu kemudian ia juga menggunakan logika yang sesuai dengan aturan dalam hukum Islam. Demikian cara atau metode ijtihad yang ia lakukan, adakalanya merujuk kepada makna lahiriyah nash, jika memang nash tersebut sesuai dengan realitas masalah yang sedang dikajinya.

Adakalanya ia juga menganalogikan masalah tersebut dari nash-nash yaitu qiyas, atau dengan menimbang realitas maslahah yang dihadapinya dengan menggunakan kaidahkaidah umum yang digali dari dalil-dalil alQuran dan as-Sunnah seperti istihsan, maslahah mursalah, urf, sad adz-Dzariah dan yang lainnya. ${ }^{17}$ Adapun cara istihsan ${ }^{18}$ yang digunakan alZuhaili yaitu dengan mengunggulkan (memakai) qiyas khafi dan meninggalkan qiyas jali karena ada petunjuk untuk itu, dimana istihsan ini disebut dengan istihsan qiyasi. Atau dengan cara Pengecualian masalah juziyah dari Ashal yang bersifat kully atau dari kaidahkaidah yang berlaku umum karena ada dalil (petunjuk) khusus yang mengharuskan hal tersebut yang disebut dengan istihsan istisnai.

Sedangkan al-Zuhaili di dalam metode maslahah mursalah yaitu dengan menentukan sebuah hukum yang dapat memperbaiki peraturan syariat atau tujuan syariat (maqasyid alsyariah) yang sebelumnya tidak ada ketentuan dalil dalam syariat, sehingga dapat terwujud menarik kebaikan (jalbu al-mashalih) dan menolak kerusakan (daru al-mafasid). ${ }^{19}$ Sedangkan dalam urf yang digunakan oleh Al-Zuhaili adalah urf yang sudah berlaku secara umum dari masa sahabat dan sesudahnya yang tidak bertentangan dengan nash syara" dan kaidah-kaidah dasar. Adapun sadd az-Dzari"ah yang digunakan az-Zuhaili yaitu untuk menentukan apakah suatu perbuatan dilarang atau tidak, karena ia bisa menjadi sarana (adz-dzariah) terjadinya suatu perbuatan lain yang dilarang. ${ }^{20}$

\section{Konsep Riba Perspektif Wahbah Zuhaili}

Permasalahan dalam riba yang terdapat dikalangan masyarakat Islam sering terdapat berbedaan perndapat dan jenis riba itu sendiri. Mengenai masalah ini, Wahbah al-Zuhaili yang merupakan cendikiawan muslim kontemporer memberikan pendapatnya terhadap permasalahan dan jenis-jenis riba. Menurut Wahbah al-Zuhaili yang dikutif dari Ibnu Rifai

\footnotetext{
17 Ibid., hlm. 199

${ }^{18}$ Al-Ghozali, Al-Mustashfa, Beirut Lebanon, juz 1, hlm, 137

${ }^{19}$ Wahbah Az-Zuhaily. Usulul Fiqh Al-Islamy, op.cit. hlm.757

${ }^{20}$ http://eprints.unwahas.ac.id/980/4/BAB\%20III.pdf. Diakses pada tanggal 12 Agustus 2020.
} 
menyatakan bahwa yang dimaksud riba adalah nilai tambahan dalam transaksi emas, perak dan seluruh jenis makanan. ${ }^{21}$ Jenis-jenis barang yang termasuk dalam barang riba ada enam macam yaitu:

1. Emas

2. Perak

3. Gandum

4. Barley/jelai

5. Kurma

6. Garam

Selain yang disebutkan di atas, setiap barang yang mirip karakterristiknya dengan enam barang tadi maka termasuk juga barang ribawi. Seperti mata uang karena merupakan alat tukar pengganti emas dan perak. Atau makanan pokok seperti nasi, jagung, atau juga buah-buahan seperti kismis, buah tin, ataupun makanan yang berguna seperti jahe. ${ }^{22}$ Mengenai jenis-jenis riba. Riba hanya diharamkan pada setiap makanan yang ditakar ataupun yang ditimbang. ${ }^{23}$ Menurutnya riba terbagi tiga macam yaitu:

1. Riba fadhl, jual beli dengan tambahan pada salah satu jenis barang yang dipertukarkan, tidak yang lain. ${ }^{24}$ Dalam pengertian lain riba fadhl adalah

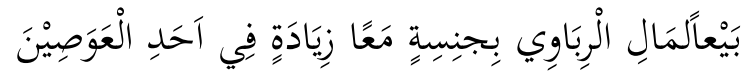
"Jual beli harta ribawi dengan jenis yang sama disertai penambahan harga pada salah satu barangnya"

2. Riba yad, jual beli disertai penangguhan serah terima dua barang yang dipertukarkan atau salah satunya. ${ }^{25}$ Dalam pengertian lain riba yad adalah

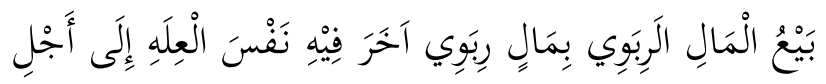

"Jual beli harta ribawi denga harta ribawi lainnya denga ilat yang sama serta ditempokan (penukarannya)"

3. Riba nasiah, jual beli yang ditangguhkan pada amsa tertentu. ${ }^{26}$

Metode penjualan ini sangat riskan kecuali penjualnya merupakan orang yang sangat kita kenal dan kita percayai.

Esensi dari riba yang mendapatkan peringatan di awal syariat ketentuan tentang riba ini sebagai diperingatkan oleh syariat agar dijauhi adalah riba nasiah. Dalam kasus ini maka, Wahbah Zuhaili menyatakan:

\footnotetext{
${ }^{21}$ Wahbah Zuhaili, al-Figh al-Islam wa Adillatuhu, Juz 4 (Damaskus: Darul Fiqr, 1985), hlm.660.

${ }^{22}$ Musthafa al-Bigha, Loc, cit,Juz 6, hIm. 57

${ }^{23}$ Wahbah Zuhaili, al-Figh al-Islam wa Adillatuhu, Juz 4 (Damaskus: Darul Fiqr, 1985), hlm.660

${ }^{24} \mathrm{lbid}$. hlm. 661

${ }^{25} \mathrm{Ibid}, \mathrm{hlm} .662$

${ }^{26} \mathrm{lbid}$, hlm. 663
} 


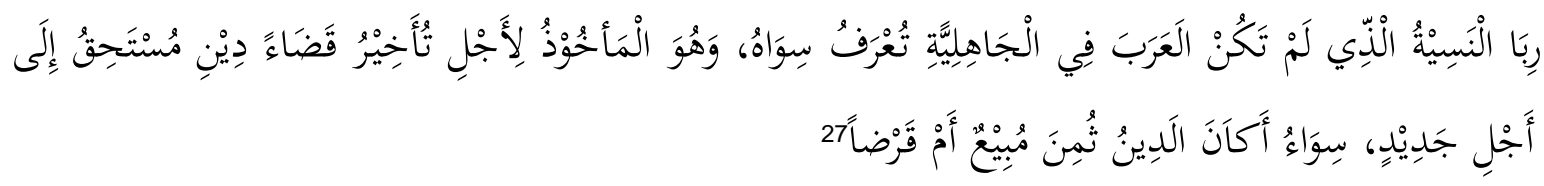

"Riba jahiliyah adalah riba yang sangat terkenal di masyarakat Arab dulu, bahkan mereka tidak pernah mengenal riba yang selainnya dalam sejarah. Riba ini dipungut karena alasan tertunda pelunasan utang sehingga perlu didaur ulang (restrukturisasi) denga waktu yang baru, bauk akibat utang karena penundaan pembayaran harga barang yang dibeli atau akibat utang piutang"

Istilah riba nasi'ah sendiri disebutkan oleh Allah SWT pada QS. ar-Rum : 39.

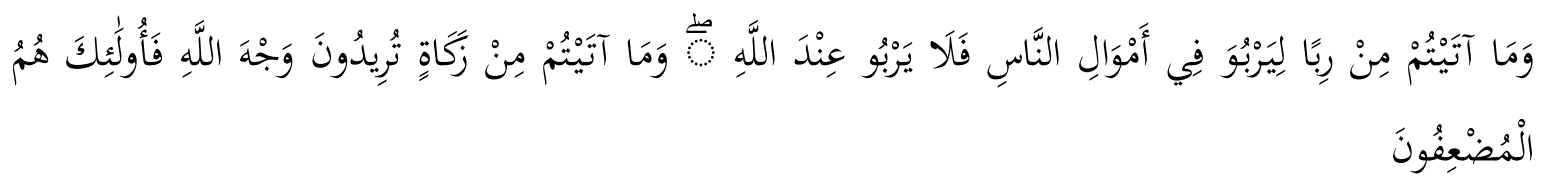

"Dan sesuatu riba (tambahan) yang kamu berikan agar dia bertambah pada harta manusia, maka riba itu tidak menambah pada sisi Allah. Dan apa yang kamu berikan berupa zakat yang kamu maksudkan untuk mencapai keridhaan Allah, maka (yang berbuat demikian) itulah orang-orang yang melipat gandakan (pahalanya)." 28

Seperti yang disampaikan oleh Wahbah Zuhaili bahwa jenis riba nasi'ah adalah jenis riba yang bersangkutan barang dengan barang dan riba ini menjadi riba yang pertama dikenal dikalangan bangsa Arab, selain itu riba nasi'ah termasuk dalam kategori adh'afan mudha'afah (berlipat ganda hampir dua kali lipat) seiring dengan penundan jatuh tempo. Diantaranya:

1. Riba Dalam Penukaran Uang dengan Uang

Wahbah al-Zuhaili mengungkapkan bahwa transaksi bisnis yang terjadi pada lembagalembaga perseroan jika dikaji lebih dalam banyak terdapat kesamaran (syubhaat) yang mengarah pada sistem riba. Namun ia memiliki peranan yangdominandalam memenuhi kepentingan dan kebutuhan publik. Sehinggajikaditiadakan maka masyarakat akan mengalami kesulitan dalam bidangekonomi. Karenanya dapat diperbolehkan dengan catatan hanya sekedar untuk menghilangkan kesulitan meskipun didalamnya terdapat unsur riba. Dalam hukum riba Wahbah al-Zuhaili mengatakan unsur riba dalam transaksi keuangan adalah riba nasiah, salah satunya dalam konsep penukaran uang berbeda bentuknya yang berputar di masyarakat secara menyeluruh. Uang sendiri menurut Sami Hamud sebagaimana dikemukakan Wahbah Zuhaili dalam kitab al-Mu'amalatul Maliyyah alMu'ashirah adalah setiap sesuatu yang digunakan sebagai media pertukaran yang mencerminkan tsaman atau harga bagi sesuatu (tsamanul asyya') dan simbol nilai (miqyas lil qiyam).

\footnotetext{
${ }^{27} \mathrm{Ibid,hlm} .670$

${ }^{28}$ Departemen Agama RI, Al Qur'an dan Tafsirnya ( Jakarta: Lembaga Percetakan Departemen Agama RI, 2009), hlm. 765
} 


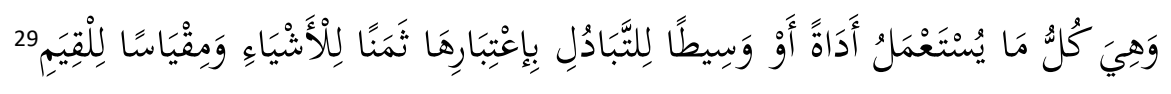

"Nuqud atau uang adalah setiap sesuatu yang digunakan sebagai media pertukaran yang mencerminkan harga sesuatu dan ukuran atau simbol nilai,".

Sedangkan menurut Muhammad Rawwas Qal'ah Ji, uang atau yang sering disebut naqd adalah sesuatu yang dijadikan harga (tsaman) oleh masyarakat. Bisa terdiri dari logam atau kertas yang dicetak dan diterbitkan oleh lembaga keuangan yang memiliki otoritas untuk menerbitkannya.

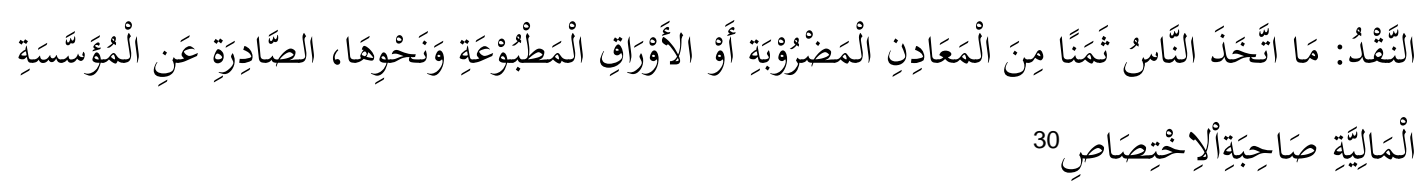

"Naqd atau mata uang adalah sesuatu yang dijadikan harga (tsaman) oleh masyarakat, baik terdiri dari logam atau kertas yang dicetak maupun dari bahan lainnya, dan diterbitkan oleh lembaga keuangan pemegang otoritas". Dari dua pengertian yang kami suguhkan tampak dengan jelas bahwa ternyata mengenai soal uang mengalami perubahan bentuk"

Dulu yang digunakan adalah koin emas atau perak, tetapi sekarang keduanya sudah tidak berlaku di masyarakat umum. Sedang yang berlaku sekarang adalah uang kertas. Sifat ribawi ini memiliki konsekuensi uang tidak boleh diperjualbelikan kecuali dengan yang sama, sejenis, dan secara tunai sebagaimana emas dan perak. la hanya bisa diperjualbelikan dengan yang sama dan sejenis serta tunai. Sifat ribawi ini memiliki konsekuensi uang tidak boleh diperjualbelikan kecuali dengan yang sama, sejenis, dan secara tunai sebagaimana emas dan perak. la hanya bisa diperjualbelikan dengan yang sama dan sejenis serta tunai.

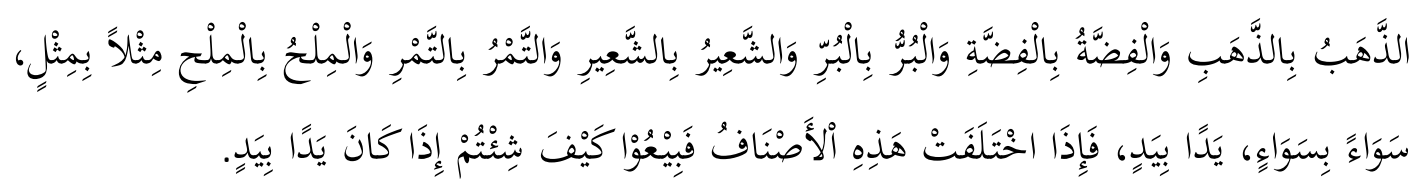

"(Jual-beli) emas dengan emas, perak dengan perak, gandum dengan gandum, syair dengan syair, kurma dengan kurma, dan garam dengan garam (dengan syarat harus) sama dan sejenis serta secara tunai.Jika jenisnya berbeda, juallah sekehendakmu jika dilakukan secara tunai," (HR Muslim).

\footnotetext{
${ }^{29}$ Wahbah Az-Zuhaili, Al-Mu'amalatul Maliyyah Al-Mu'ashirah, (Damaskus, Darul Fikr, cet ke-6,2008 ), hlm. 150

${ }^{30}$ Muhammad Rawas Qal'ah Ji, Al-Mu'amalat Al-Maliyah Al-Mu'ashirah fi Dhau'il Figh was Syari'ah, (Beirut, Darun Nafa'is, 1999 ), hlm. 23
} 


\section{Riba dalam Transaksi Keungan Asuransi}

Pendapat Wahbah al-Zuhaili terhadap perjanjian asuransi terdapat beberapa keharamannya salah satunya yaitu adanya praktik riba yang terdapat dalam Asuransi. Dalam kitabnya al-Fiqh al-Islam wa Adillatuhu mengatakan kompensasi dalam praktik asuransi jumlahnya melebihi premi yang diberikan oleh pihak penerima asuransi dab kelebihan diberikan tanpa adanya imbalan yang dianggap riba yang diharamkan. ${ }^{31}$ Untuk mengetahui bagaimana caranya adanya praktik riba dalam asuransi, dapat dicontohkan dengan seseorang dari nasabah mendapatkan musibah kecelakaan sesuai dengan yang diperjanjikan, akan tetapi dia mendapatkan jumlahnya lebih dari premi yang dikeluarkannya, hal semacam ini sering terjadi dalam asuransi pada waktu promosi untuk menarik nasabah atau pelanggan yang dilakukan pihak asuransi berupa jaminan kompensasi yang memberikan nilai lebih walaupun jumlah premi yang disetorkan baru sedikit. Ini bentuk riba yang jelas diharamkan oleh Allah SWT. ${ }^{32}$

Bahkan dengan kenyataan bahwa perusahan yang beroprasi dalam asuransi menginventasikan kepada perusahaan yang mempraktikan riba, serta menggunakan bunga atas pihak penerima asuransi apabila terjadi penunggakan pembayaran cicilan premi yang harus dibayar. ${ }^{33}$ Langkah pertama dalam pelarangan riba adalah dengan menolak bahwa dalam pinjaman riba yang pada zahirnya seolah-olah telah menolong mereka yang memerlukan sebagai langkah untuk mendekatkan diri kepada Allah SWT.

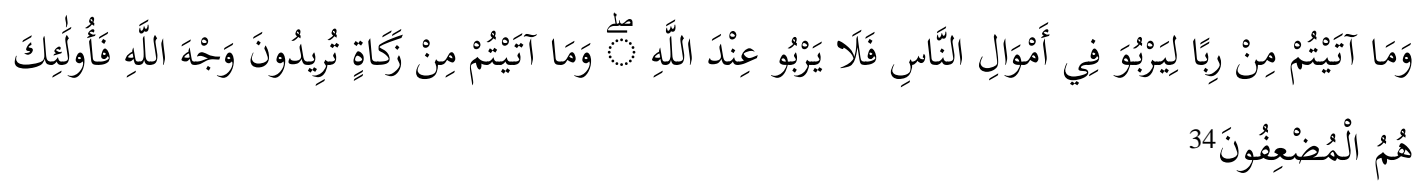

"Dan sesuatu riba (tambahan) yang kamu berikan agar dia bertambah pada harta manusia, maka riba itu tidak menambah pada sisi Allah. Dan apa yang kamu berikan berupa zakat yang kamu maksudkan untuk mencapai keridhaan Allah, maka (yang berbuat demikian) itulah orang-orang yang melipat gandakan (pahalanya)."

Ayat di atas menjelaskan bahwa walaupun manusia memberikan tambahan kepada orang lain sedangkan tambahan itu berupa riba, maka sesuangguhnya perbuatan itu tidak akan menambah dekat kepada Allah.

3. Analisis Wahbah al-Zuhaili Terhadap Persamaan Riba dan Bunga Bank

Menurut pandangan Wahbah al-Zuhaili, riba adalah tambahan pada sesuatu tertentu atau kelebihan harta dalam pertukaran satu harta dengan harta yang lain tanpa adanya sesuatu pengganti. la juga berpendapat bahwasanya landasan hukum riba yakni terdapat dalam naș al-Quran, Hadits, Ijma dan Qiyas.

\footnotetext{
${ }^{31}$ Wahbah Zuhaili, al-Fighu al-Islamy wa Adillatuhu, Juz 6, (Damaskus: Daru al-Fikr, 1985), hlm.54

${ }^{32} \mathrm{lbid}$, hlm. 105.

${ }^{33} / \mathrm{lid}, \mathrm{hlm} .105$

${ }^{34}$ Departemen Agama RI, Al Qur'an dan Tafsirnya ( Jakarta: Lembaga Percetakan Departemen Agama RI, 2009), hlm. 674
} 
Menurut Wahbah Zuhaili bunga bank termasuk bagian dari riba nasi ah. Adapun riba nasi ah biasa disebut dengan riba jahiliyah.

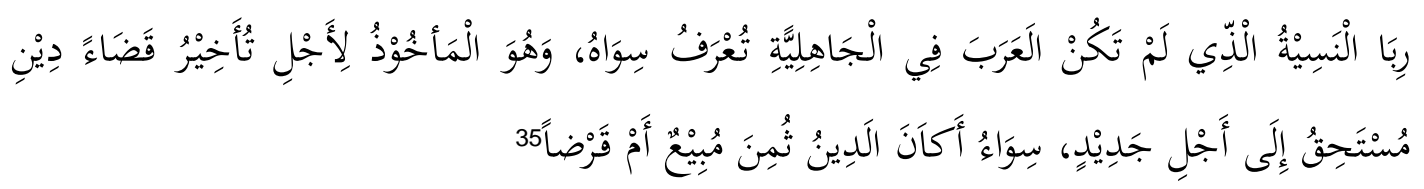

"Riba jahiliyah adalah riba yang sangat terkenal di masyarakat Arab dulu, bahkan mereka tidak pernah mengenal riba yang selainnya dalam sejarah. Riba ini dipungut karena alasan tertunda pelunasan utang sehingga perlu didaur ulang (restrukturisasi) denga waktu yang baru, bauk akibat utang karena penundaan pembayaran harga barang yang dibeli atau akibat utang piutang."

Masyarakat saat ini menyebutnya dengan pembayaran hutang yang ditunda pembayarannya. Sudah diketahui bahwasanya bank sebenarnya enggan untuk melakukan transaksi perdagangan atau investasi. Fokus perhatian bank hanya pada meminjam uang dari nasabah dan meminjamkannya kepada pihak lain yang membutuhkan. Bank memberi bunga kepada nasabah dan menarik bunga dari kreditur. Dengan demikian tugas bank hanya memperjualbelikan hutang. Selain itu, tugas bank yang kedua adalah menciptakan hutang atau meminjamkan sesuatu yang bukan hak miliknya sendiri.

Wahbah al-Zuhaili juga mengatakan mengambil bunga bank sedikit atau banyak termasuk dari riba. Saat ini pun transaksi yang mengandung riba nasi ah bisa ditemukan dalam bentuk pertukaran uang seperti membeli dolar dengan dirham tanpa serah terima di majelis dan meminjam uang dengan syarat mengembalikan dengan tambahan dengan nilai tertentu yang sudah di Begitu pula diharamkannya menyimpan uang di bank dan sekaligus bersepakat membayar pajak kepada negara dengan uang itu atau menerima bunga yang akan diberikan kepada fakir miskin.

\section{Solusi Wahbah al-Zuhaili Agar Terbebas dari Riba}

Selain menjelaskan soal keharaman riba, wahbah al-Zuhaili juga memberikan solusi bagi masyarakat khususnya muslim agar terbebas dari praktik riba nasiah yaitu Utang barang yang tidak diketahui waktu pelunasan/jatuh tempo ini sehingga berupaya menarik tambahan keuntungan seiring penundaan kembali dari waktu jatuh tempo, maka tambahan tersebut diistilahkan sebagai riba nasi'ah. Adapun bila tanpa penundaan, atau seandainya ada penundaan maka tidak ada syarat tambahan yang dipungut sebagai konsekuensi dari penguluran waktu, maka dalam kondisi seperti ini praktik jual beli semacam dinamakan dengan istilah jual beli kredit yang dijamin kebenarannya oleh syariat.

Praktik riba nasiah ini umum dilakukan oleh para niagawan Arab pada saat itu, di antaranya adalah paman Nabi SAW, yaitu Abbas bin Abdul Muthallib, dan Khalid bin Walid. Bahkan kemudian riba ini populer di kalangan ahli tafsir sebagai "Riba Abbas" atau "Riba Jahiliyyah". Jadi, esensi riba yang mendapatkan peringatan di awal syariat ketentuan

\footnotetext{
${ }^{35}$ Wahbah Zuhaili, al-Fiqh al-Islam wa Adillatuhu, Juz 4 (Damaskus: Darul Fiqr, 1985), hlm.670.
} 
tentang riba ini sebagai diperingatkan oleh syariat agar dijauhi adalah riba nasiah. Wahbah al-Zuhaili menyatakan:

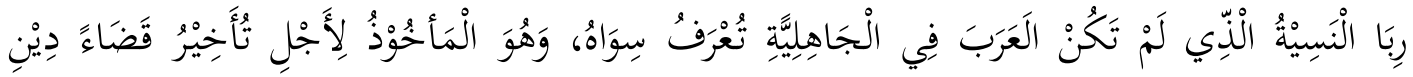

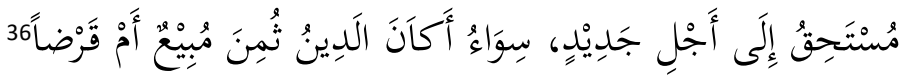

"Riba jahiliyah adalah riba yang sangat dikenal oleh masyarakat Arab kala itu, bahkan mereka tidak pernah mengenal riba yang selainnya dalam sejarah. Riba ini dipungut karena alasan tertundanya pelunasan hutang sehingga perlu daur ulang (restrukturisasi) dengan tempo yang baru, baik itu akibat utang karena penundaan pembayaran harga barang yang dibeli atau akibat akad utang piutang,"

Mengapa diperingatkan? Denga kata lain wahbah al-Zuhaili memberika solusi agar terhindar/terbebas dari riba. Karena alasan penindasan (zhulm). Sebagaimana hal ini tercermin dalam Firman Allah SWT QS an-Nisa' ayat 160-161:

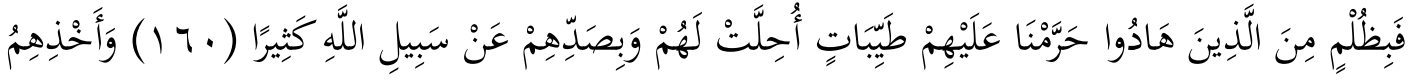

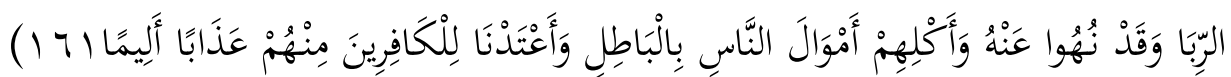

'Maka disebabkan kezaliman orang-orang Yahudi, Kami haramkan atas mereka (memakan makanan) yang baik-baik (yang dahulunya) dihalalkan bagi mereka, karena mereka banyak menghalangi (manusia) dari jalan Allah, disebabkan mereka memakan riba. padahal sesungguhnya mereka telah dilarang darinya, dan karena mereka memakan harta orang dengan jalan yang batil. Kami telah menyediakan untuk orang-orang yang kafir di antara mereka itu siksa yang pedih." 37

Istilah riba yang disebutkan dalam ayat ini penegasan mengenai riba nasi'ah yang dijelaskan oleh ayat al-Quran pada QS. ar-Rum ayat 39. Wahbah al-Zuhaili sendiri memberikan solusi dengan mengatakan bahwasanya setiap transaksi dapat terbebas dari riba jika mengakomodasi nilai keadilan yang diimplementasikan dalam masyarakat.

\section{SIMPULAN}

\footnotetext{
${ }^{36}$ Wahbah Zuhaili, al-Fiqh al-Islam wa Adillatuhu, Juz 4 (Damaskus: Darul Fiqr, 1985), hlm.670

${ }^{37}$ Departemen Agama RI, Al Qur'an dan Tafsirnya ( Jakarta: Lembaga Percetakan Departemen Agama RI, 2009), hlm. 875
} 
Wahbah al-Zuhaili dalam pemikirannya terjadinya riba, tukar menukar antara uang dengan uang dan dalam penegelolaan asuransi. Bahkan Wahbah al-Zuhaili menyamakan hukum riba dengan bunga bank yang sama-sama haram baik mengambil secara besar maupun kecil. Wahbah al-Zuhaili memberikan solusi bagi masyarakat agar terhindar dari riba dengan perlunya mengakomodasi keadilan sejak awal terhadap hukum transaksi keuangan yang ada dikalangan masyarakat secara menyeluruh agar masyarakat dapat mengetahui unsur riba yang ada dalam transaksi keuangan.

\section{DAFTAR PUSTAKA}

Abdul, Ghofur. 2016. "Konsep Riba dalam Al-Qur'an." Economica: Jurnal Ekonomi Islam. Volume 7. No. 1. Tahun 2016.

Abyan, Amir. 2006. Fiqih Muamalah. Semarang: Toha Putra.

al-Husain al-Tariqi, Abdullah Abd. 2004. Ekonomi Islam: Prinsip, Dasar dan Tujuan, Terjemahan. Yogyakarta: Magistra Insania Press.

As-Shiddiqi, Hasbi. 1975. Filsafat Hukum Islam. Bandung: Bulan Bintang.

Azim, Abdul Aziz Muhammad. 2010. Figh Muamalat. Jakarta: Amzah.

Departemen Agama RI. 2009. Al Qur'an dan Tafsirnya. Jakarta: Lembaga Percetakan Departemen Agama RI.

Ghazaly, Abdul Rahman, dkk. 2010. Fiqih Muamalat. Jakarta: Kencana Prenada Media Grup. Ghofur, Saiful Amin. 2008. Profil Para Mufasir al-Qur'an. Yogyakarta: Pustaka Insan Madani. Hadaliah, L. D., \& Maryani, S. 2020. Pengaruh Label Halal Terhadap Pilihan Konsumen Gerai Indomart Panumbangan Kabupaten Ciamis. Mutawasith: Jurnal Hukum Islam, 3(1), 87-105.

http://eprints.stainkudus.ac.id/1154/7/7.\%20BAB\%204.pdf. Diakses pada tanggal 12 Agustus 2020.

http://eprints.unwahas.ac.id/980/4/BAB\%20III.pdf. Diakses pada tanggal 12 Agustus 2020. Jamaludin, J., \& Gozali, D. 2018. Etika Bisnis Islam Di Kalangan Pedagang Pasar Manaqib TQN Suryalaya. MUTAWASITH, 1(1), 1-18.

Qal'ah Ji, Muhammad Rawas, 1999. Al-Mu'amalat Al-Maliyah Al-Mu'ashirah fi Dhau'il Figh was Syari'ah. Beirut: Darun Nafa'is.

Rahayu, Lisa. 2010. Makna Qaulan dalam al-Qur'an; Tinjauan Tafsir Tematik Menurut Wahbah al-Zuhaili. Skripsi Sarjana, Fakutas Ushuluddin Univesitas UIN SUSKSA Riau: Pekanbaru.

Rifai, Moh. 1998. Mutiara Fiqih. Semarang: CV. Wicaksana.

Syafe'i, Rahmat. 2015. IImu Ushul Fiqih, cet.5. Bandung: Pustaka Setia.

Zuhaili,Wahbah. 1985. al-Figh al-Islam wa Adillatuhu, Juz 4. Damaskus: Darul Fiqr. 